\title{
A Gestão de Design como estratégia organizacional em uma empresa de complementos decorativos termocolantes de Londrina-PR
}

\author{
The Design Management as an organizational strategy of a decorative termocolante \\ complement's company from Londrina - $P R$
}

\author{
BUSO, Vanessa Zanardo; Especialista; \\ Universidade Estadual de Londrina \\ vanessabuso@hotmail.com \\ MARTINS, Rosane Fonseca de Freitas; Doutora; \\ Universidade Estadual de Londrina \\ rosane@uel.br
}

\begin{abstract}
RESUMO
Este artigo tem como objetivo propor ações de design para o Departamento de criação de uma empresa de complementos decorativos termocolantes de Londrina-PR, provenientes de um estudo de caso utilizado como metodologia de pesquisa. Tais ações se estendem aos demais departamentos da empresa, fundamentando uma estratégia de Gestão de Design. Como resultado esperado, pretende redirecionar a estrutura organizacional da empresa ao demonstrar e salientar a real importância do vínculo estratégico entre a Gestão do Design e o departamento de Criação para consequente viés de produção lucrativo e organizado.
\end{abstract}

Palavras Chave: Gestão de Design; estratégia; termocolantes

\begin{abstract}
This article aims to propose design actions, to the Criative Department of a company at Londrina-PR, from a case study used as research methodology. These actions extend to the other departments, establishing a Management design strategic. Therefore, this work aims to redirect the company's organizational structure from demonstrate and emphasize the real importance of the strategic link between Management design and the Criative Department to the eventual profitable and organized business
\end{abstract}

Keywords: Management Design; strategic, termocolantes

\section{Introdução}

O trabalho aqui proposto aborda uma experiência de gestão de design a partir de uma análise real e objetivada de uma pequena empresa do ramo da moda (neste trabalho intitulada como empresa A) atuante no mercado de complementos decorativos destinados à indústria de confecção do Paraná; atendendo principalmente as regiões que compreendem os municípios de Londrina, Maringá e Cianorte.

De acordo com a FIEP (2008), da distribuição espacial dos estabelecimentos da indústria têxtil no Brasil, o estado do Paraná aparece na quinta posição com aproximadamente 744 estabelecimentos industriais e uma participação de 6,59\%.

O “Corredor da Moda” é uma das principais aglomerações do setor têxtil-confecções 
formada pelo eixo Londrina - Apucarana - Maringá - Cianorte (norte e o nordeste do Paraná), que é constituído por uma aglomeração de empresas do chamado complexo vestimentar, beneficiamento, fiação, tecelagem, vestuário, uniformes, bonés, lavanderias e serviços de acabamento, que vem adquirindo importância nacional [...] (APL, 2006, p.04)

O mercado têxtil abrange diversos tipos de indústrias e a fabricação de complementos decorativos tais como etiquetas, tags, botões, apliques termocolantes e bordados se incluem nesse mercado.

Barone (2009) afirma que os fabricantes de etiquetas para roupas enfrentaram a crise, que causou estoques mais controlados nas confecções e no varejo de moda, com uma estratégia que combina produtos mais baratos e novos mercados, uma vez que as confecções reduziram os estoques, mas ainda assim querem produtos e artigos com variedade e alto valor agregado.

Nesse sentido, a empresa $A$ trabalha a diferenciação dos seus produtos mantendo uma linha que disponibiliza etiquetas termocolantes (opção de etiqueta feita com variados tipos de tecidos e acabada com silicone prensado) que economizam a necessidade de costura destas nas peças; e apliques termocolantes que utilizam materiais como pedras semelhantes aos cristais Swarovisk, metais sextavados e outros artigos. Tudo para disponibilizar à indústria de confecção do Paraná um acabamento diferenciado para as suas peças.

A indústria brasileira de complementos decorativos (que produz zíperes, etiquetas, apliques e botões), fatura, anualmente, aproximadamente um bilhão de reais. (BARONE, 2009).

Apesar da excelência em qualidade de seus produtos e serviços, a empresa A necessita de uma efetiva consistência organizacional e projeção mercadológica para que seja de fato uma empresa lucrativa e de boa aceitação pelos seus consumidores fiéis e pelos consumidores eventuais.

Dessa forma, o problema que norteará o desenvolvimento deste trabalho é: qual a capacidade empresarial de reconhecer e executar a união entre o processo criativo e a gestão do design como ferramenta precursora para se estabelecer o fim da utilização de estratégicas empíricas na solução de problemas organizacionais?

Em acordo, o artigo propõe contribuições da gestão do design ao bom funcionamento do departamento criativo da empresa $A$ e se estende a demonstrar a importância do pensamento do design como uma ferramenta de criação de valor em uma organização em sua totalidade. Nesse sentido, afirma Best (2006) que o design encontra-se intrinsecamente ligado ao negócio ou à empresa, de maneira que consegue adicionar ou criar valor para esta.

Dentre os objetivos específicos, o projeto visa estudar os processos de gestão de design e o design thinking como fundamentação teórica para delimitar, de acordo com a metodologia aplicada por Emídio (2006), a coleta de dados.

Seguidamente, apresenta o estudo de caso e propõe medidas em nível operacional e estratégico no âmbito da gestão e do design, buscando efetivar de maneira progressiva a consistência organizacional da empresa $A$.

A proposta de ações de gestão de design orientadas ao departamento de pesquisa e criação da empresa A como precursoras a ações de gestão e design em nível organizacional se justifica na medida em que o departamento citado é o responsável pela etapa do processo criativo, e este por sua vez correlaciona-se ao departamento administrativo e paralelamente delimita o departamento de produção; ou seja, o departamento de criação está 'entrelaçado' a esses dois departamentos que constroem a empresa A.

Ainda sobre justificativa, no departamento de criação da empresa A encontra-se o profissional de design, o designer; que influenciará positivamente a disseminação das ações de GD sobre toda a organização.

A metodologia utilizada neste trabalho foi uma pesquisa de natureza exploratória "[...] que tem como objetivo principal o aprimoramento de idéias ou a descoberta de intuições" (GIL, 2002, p. 41). A pesquisa exploratória utiliza um planejamento flexível e neste artigo ela delineia-se a partir de um estudo de caso, que segundo Yin, (2001) traduz-se como uma ferramenta empírica que examina 
e apura um fenômeno contemporâneo real, beneficiando o desenvolvimento prévio de proposições teóricas que conduzem a coleta de dados e análise desses dados.

Para uma efetiva utilização do estudo de caso, antecede-se uma pesquisa de dados primários que instrumenta abordagens para a realização dos procedimentos do estudo de caso. Enfim, aplica-se uma ferramenta de diagnóstico composta por uma entrevista com o roteiro utilizado a partir de um modelo estruturado denominado "Modelo de checagem de utilização da Gestão de Design em MPEs do vestuário de moda." (EMIDIO, 2006, p.81 a 84).

Dessa forma, o estudo de caso neste artigo estrutura-se pela entrevista citada e por estratégias complementares de etnografia e observação. A etnografia compreende o estudo, pela observação direta e por um período de tempo, dos costumes de um grupo particular, uma associação de poucos ou muitos elementos. Dessa forma a utilização da etnografia nesse trabalho se dá por conclusões autorais.

A proposta de estudo de caso neste artigo permite detectar e propor ações com base nas necessidades reais da empresa em questão. Dessa forma, durante o estudo de caso foram verificadas problemáticas que envolvem áreas específicas como Marketing, Gestão pessoal e Gestão da qualidade, as quais não serão abordadas com ênfase. Respeitando a problemática deste projeto o embasamento será dedicado à aplicação de medidas que envolvam gestão e design em curto, médio e longo prazo.

\section{Gestão do design: contextualizando}

Uma empresa é essencialmente conseqüência de sua cultura organizacional. De acordo com Emídio (2006), uma empresa compreende sua cultura quando entende o desafio de criar novas formas de organização e de administração para gerar uma revolução cultural. Dessa maneira, cabe ao quadro dirigente de uma empresa dar forma a uma nova cultura, afim de que esta passe a determinar o estilo e a filosofia administrativa da empresa.

A busca por uma revolução cultural dentro de uma empresa é uma estratégia que abarca todo o sistema de atividades dessa empresa. Comparativamente à estratégia de inovação de valor de Mauborgne e Kim (2005) a evolução cultural também exige da empresa que ela se reoriente para empreender um salto no valor, tanto para seus consumidores quanto para ela própria.

Entendemos como conhecimento organizacional todo o conhecimento que a organização dispõe, além dos conhecimentos óbvios como o objetivo e o explícito, incluímos o cultural (que envolve tradição) e o conhecimento tácito (aquele adquirido ao longo dos anos, por experiência). (DEMARCHI, FORNASIER, MARTINS, 2012. Pg. 176).

Empresas que reconhecem a necessidade de uma revolução cultural organizacional seguem em busca de recursos para enfrentar a globalização. A globalização trouxe uma era em que empresas e organizações se enfrentam diariamente para se manterem efetivas no mercado, driblando a concorrência. Mauborgne e Kim (2005) afirmam que tradicionalmente as empresas se preocupam em criar mais valor para os clientes a um custo mais alto ou criar o mesmo valor que a concorrência a um custo menor. Porém, em contrapartida a essa situação está o universo crescente de organizações em busca de diferenciação e liderança de custos ao mesmo tempo; o que os autores afirmam ser a conquista efetiva de empresas de sucesso.

Essa esfera contemporânea de produção tem como fundamental aliada a Gestão do design. Para Mozota (2002) se o fundamento da gestão do design é identificar e comunicar as maneiras pelas quais o design pode contribuir para a estratégia de uma empresa, então identificar oportunidades para o design é o primeiro passo nesse sentido.

E como definir gestão do design? Best (2006), após analisar vários conceitos sobre a perspectiva de diferentes autores descreve que o gestor de design tem o papel de gerenciar design e dessa forma,

Os aspectos importantes da gestão do design estão em entender os objetivos estratégicos de uma organização e o como o design pode desempenhar um papel 
e efetivamente por em prática as formas e meios, as ferramentas e os métodos, as equipes e os requisitos de planejamento, a paixão e o entusiasmo, para atingir esses objetivos como resultados de sucesso. (BEST, 2006, p. 12)

Para o Centro Português de Design (1997), a gestão do design apóia-se em dois pilares. Dentro de um projeto de produto torna-se uma atividade que se ocupa em gerir os recursos humanos e materiais desde o nascimento de uma idéia ate seu lançamento no mercado. Por outro lado, dentro da empresa, o gestor de design procura proporcionar condições e meios favoráveis para o nascimento de novos produtos.

Retomando ao raciocínio de Mozota acima descrito, quais seriam então as oportunidades do design perante GD?

Em uma organização, o design pode afetar a gestão em diferentes níveis, sendo um ativo estratégico, tático ou operacional junto à definição de metas de longo prazo e no dia-a-dia de tomada de decisões.

Design é uma função, um recurso e uma maneira de pensar dentro das organizações que pode ser ativo no pensamento estratégico, nos processos de desenvolvimento e, fundamentalmente na implementação de projetos de sistemas e serviços; as maneiras pelas quais uma organização se conecta aos seus clientes e partes interessadas. (BEST, 2006, p. 16)

O departamento de criação de produtos de uma empresa torna-se referencial inicial de um processo estratégico e operacional conjunto que visa estabelecer processos e meios para o desenvolvimento efetivo de soluções mercadológicas que proporcionam qualidade, valor e inovação ao mercado consumidor.

Por outro lado, o design no departamento de criação alavanca outra vantagem competitiva que diz respeito à otimização de custos. A busca por materiais adequados e a adequação de processos de testes com matéria-prima se estende à preocupação do designer em realizar junto ao departamento de produção da empresa a adequação dos processos de fabricação. Nesse sentido, faz-se necessário o compromisso da gerência de produção em atuar juntamente ao designer para a constante evolução e fiscalização destes processos, evitando desperdícios.

Outro ponto também alinhado pelo designer no departamento de criação é a questão da identidade visual da organização. Esta transmite ao público as características e os elementos que compõem a imagem da marca e de seus produtos. Essas características devem atender as expectativas de seus clientes, ao facilitar o contato visual destes com a matéria-prima, com as formas, os shapes e as tendências utilizadas pela empresa em cada coleção. Paralelamente, o designer de moda estende aos profissionais de design gráfico e de marketing o desenvolvimento dos materiais de comunicação visual para fazer com que os consumidores realizem uma fácil associação com a marca.

Nota-se que as funções operacionais do design se integram a todos os setores da empresa. Dessa forma, a gestão do design trabalha em prol dessa integração traduzindo as funções operacionais em uma função estratégica de formalizar um design corporativo consistente. É necessário estabelecer um programa de design e não apoiar-se em um designer. O gestor de design estabelece junto a empresa a necessidade de conceber um processo que diminua a incerteza inerente ao desenvolvimento de produtos, e quanto mais áreas forem correlacionadas, menores as chances de fracasso. Assim, faz-se necessária que a cultura organizacional da empresa seja propícia à inovação e ao desenvolvimento progressivo.

De acordo com o Centro Português de Design (1997, p. 24 e 25), resumidamente em tópicos descrevem-se as atribuições da GD,

\section{1)A partir da administração ou em nível estratégico:}

-Diagnosticar a situação da empresa, os seus produtos e as suas tecnologias principais, em relação aos concorrentes mais próximos.

-Definir os campos de atuação futuros, em termos de tecnologia, produtos e mercados. 
-Determinar as opções em função dos pontos fortes e fracos da empresa.

-Integrar no desenvolvimento as funções de Marketing, produção, engenharia do produto, finanças, design, etc. para descobrir novas oportunidades e riscos.

-Fazer do design e da inovação algo cultural da empresa, responsável pelo lucro ao longo prazo.

\section{2)Em nível operacional:}

-Determinar a natureza de um projeto, avaliando as diferenças entre objetivos e capacidade da empresa.

-Organizar o processo de desenvolvimento que estabeleça a extensão de cada fase e os níveis de decisão, garantindo um fluxo de informação até a administração e os elementos da equipe.

-Selecionar os elementos da equipe e organizá-la: escolhendo os profissionais apropriados, mantendo-os ou fazendo mudanças necessárias, estabelecendo procedimentos para solução de conflitos.

Sendo assim, designers do departamento de criação unem-se aos demais profissionais de uma organização a fim de concretizar um projeto de produto de valor agregado, coerente com as condições exigidas para a sobrevivência de uma empresa contemporânea. Dessa forma, essa união faz-se efetiva quando os profissionais de uma organização trabalham como 'pensadores de design'; assunto relatado no próximo tópico.

\section{A gestão do design e o design thinking}

O processo de design baseado no design thinking representa uma mudança radical na maneira de fazer negócios e isso pode ajudar a levar o design a diferentes níveis da organização e não somente no escopo do projeto. (DEMARCHI, FORNASIER, MARTINS, 2010).

A idéia multidisciplinar para o desenvolvimento de projetos de design em organizações defendida pela gestão do design encontra subsídio no design thinking. O design thinking, de acordo com definições expostas pelas autoras Demarchi, Fornasier e Martins (2010), deriva do termo thinking no sentido de thinking through, que significa pensar por meio de; pensar por meio de como os designers fazem. Essa definição envolve a visualização de problemas e conceitos para o desenvolvimento de cenários e estratégias baseadas nos métodos dos designers.

O que o design thinking propõe é que os processos operacionais relacionados ao projeto de produto se concretizem como estratégias criativas que envolvam todos os departamentos organizacionais e quando necessário envolvam também profissionais exteriores.

Para o design thinking, o processo de design se adéqua à natureza de cada projeto e não constitui um projeto linear, pois possui muitos ciclos responsáveis por permitir a natureza interativa do design e por acomodar insights em cada estágio do processo, conforme defendem Demarchi, Fornasier e Martins (2010).

Nesse sentido, Brown (2010) descreve que o continuum dos processos de inovação não segue uma linearidade e sim uma sobreposição de espaços. Esses espaços seriam: a inspiração, que advém de um problema ou uma oportunidade que motiva a busca por soluções; a idealização, o processo de gerar, desenvolver e principalmente testar idéias; e a implementação. Dessa forma, os projetos podem percorrer esses espaços mais de uma vez à medida que a equipe lapida suas idéias e explora novos direcionamentos.

Dessa forma, o pensamento de design representa um desafio para as empresas mais tradicionais que partem do pressuposto que identificada uma oportunidade, lida-se com os números disponíveis para assegurar-se e então otimiza-se. Ou seja, fases definidas para criação de soluções. Porém, muitas questões precisam ser revistas antes que se possa gerar uma nova idéia.

Analisando as idéias de David Kelley, fundador da empresa de consultoria em design IDEO e 'pensador de design'; na década de 1980, as propostas de design enviadas aos clientes se resumiam 
nas seguintes fases de processo: compreensão, observação, criação e protótipo. Os clientes queriam apenas que o processo se concentrasse nas duas últimas fases, tratando a compreensão e a observação como perda de tempo. Porém, Kelley percebeu que eram nessas fases iniciais que surgiam as grandes idéias; o que passou a separar os resultados da sua empresa de outras em consultoria em design e gestão. "Depois disso me dispus a só aceitar um trabalho em que fossem respeitadas essas fases" (HSMMANAGMENT, 2009, p. 185).

As fases de compreensão e observação são muito importantes para um projeto, pois são elas que delineiam os limites e as restrições que cabem à execução de uma ou mais idéias. Para Brown (2010), a aceitação e disposição em trabalhar com restrições constituem o fundamento do design thinking.

As restrições podem ser mais bem visualizadas em função de três critérios sobrepostos para boas idéias: praticabilidade (o que é funcionalmente possível num futuro próximo); viabilidade (o que provavelmente se tornará parte de um modelo de negócio sustentável); e desejabilidade (o que faz sentido para as pessoas). (BROWN, 2010, p. 18)

Dessa forma, os designers thinkers trafegam por meio das restrições observadas e dessa forma a criatividade vêem a tona, focando-se no projeto. A partir disso, a clareza, o direcionamento e os limites de um projeto bem definido são vitais para sustentar a energia criativa.

A sustentação da energia criativa por sua vez, encontra respaldo na idéia agregadora que o design thinking e a gestão do design compartilham; a idéia da multidisciplinaridade de uma equipe dentro de um projeto. Idéias criativas provêm de equipes criativas e essas equipes são fruto de um trabalho interdisciplinar dentro das organizações. Percorrer as etapas que conduzem um projeto para alcançar bons resultados só é possível com o desenvolvimento de um projeto que considera a sobreposição dessas etapas (valor agregado de insights e inputs) e o trabalho em conjunto. Dessa forma, todos os departamentos que percorrem um projeto até a sua conclusão em produto devem trabalhar idéias coletivas, sendo todos responsáveis por elas.

Por outro lado, o processo de definição de protótipo também encontra no design thinking um grande aliado. Para Demarchi, Fornasier e Martins (2010), o designer thinker avança o seu processo projetual e grava suas observações e idéias visualmente. Em seguida, sua cultura o faz sentir a necessidade da realização de um protótipo, que não é apenas testar idéias finais e sim validar um processo de criação e expressar o pensamento visual.

O protótipo torna a idéia tangível ou intangível. A partir dele testa-se os materiais evitando o desperdício destes no processo produtivo, além de proporcionar uma visão prévia do sistema produtivo e dos meios de otimização que podem ser planejados para a produção em série do produto prototipado. Ou seja, dentre várias colaborações, a construção de um protótipo permite avaliar a idéia para definir as delimitações do projeto, identificando novas direções quando necessário.

Enfim, pode-se mencionar o processo de design thinking como um processo de viver design e não apenas fazê-lo. Lockwood (2006) definiu alguns aspectos que resumem o design thinking. Primeiramente, como ponto chave, o desenvolvimento profundo de uma pesquisa de campo, pois a empatia (assistir, ouvir, discutir e compreender) pode ser uma fonte de inspiração e auxílio para atingir os insights dos consumidores, descobrindo necessidades desvinculadas.

Posteriormente, a formação de grupos multidisciplinares para realização de projetos. A participação ativa de todos os departamentos da empresa e também de clientes e parceiros além de gerar mais idéias, cria uma rede de fidelidade difícil de ser destruída, Brown (2010).

Em seguida, a capacidade de acelerar o aprendizado pela visualização, experimentalismo e criação de protótipos rápidos. Dessa forma, os líderes empresariais devem sempre incentivar a experimentação, para dar margem e aceitar o fracasso, pois não há nada de errado com o fracasso, contanto que ele ocorra no começo do projeto e se torne fonte de aprendizado pela equipe, Brown (2010).

Por fim, a habilidade de gerar visualizações de conceitos, ligada à importância de integrar a 
análise de negócio durante o processo, e não no final deste; ou seja, combinar a idéia com aspectos estratégicos tradicionais, o que gera um ponto de vista mais completo. Para Brown (2010), isso significa estar preparado para não desacelerar o processo de design como, por exemplo, com inconvenientes orçamentários ou procedimentos burocráticos. Esses aspectos devem estar sempre alinhados à medida que os projetos avançam.

Dessa forma, foi possível relacionar aos aspectos que resumem o design thinking para Lockwood, descrições também posicionadas por Brown, correlacionando os mesmos conceitos. Dessa forma, o "pensar por meio de como os designers fazem" e assim executar os projetos de produto de uma organização como ferramenta de inovação e resultado positivo comporta que "O design thinking tem suas origens no treinamento e na prática profissional de designers, mas estes são princípios que podem ser estendidos a todas as áreas de atividade." (BROWN, 2010, p. 225)

\section{Metodologia}

Após conceituação e fundamentação de pontos importantes da gestão do design e do design thinking como aliados organizacionais, utilizar-se-ão esses pontos como norteadores na obtenção das propostas de ação em nível operacional e estratégico para a empresa A.

Porém, para se chegar à obtenção dessas propostas faz-se um estudo da empresa $A$ considerando alguns aspectos e procedimentos descritos e definidos a seguir.

De acordo com Gil (2002), classificar pesquisas em pesquisas exploratórias, descritivas ou explicativas é muito conivente para o estabelecimento de seu conteúdo teórico, ou seja, para possibilitar uma aproximação conceitual. No entanto, para analisar os fatos do ponto de vista empírico, para confrontar a visão teórica com os dados da realidade torna-se necessário traçar um modelo conceitual e operativo de pesquisa.

Dessa forma, ainda por Gil (2002), o delineamento de uma pesquisa consolida o planejamento desta em sua dimensão mais ampla, o que envolve tanto a diagramação como também a previsão de análise e a interpretação da coleta de dados. Por outro lado, o delineamento de uma pesquisa considera o ambiente da coleta de dados e como são controladas as variantes envolvidas, dando ênfase para os procedimentos técnicos de coleta e análise de dados.

Nesse sentido Yin, completa que

No sentido mais elementar, o projeto de pesquisa é a seqüência lógica que conecta os dados empíricos às questões de pesquisa iniciais do estudo e, em última análise, às suas conclusões. Coloquialmente, um projeto de pesquisa é um plano de ação para se sair daqui e chegar lá, onde aqui pode ser definido como o conjunto inicial de questões a serem respondidas, e lá é um conjunto de conclusões (respostas) sobre essas questões. Entre "aqui" e "lá" pode-se encontrar um grande número de etapas principais, incluindo a coleta e a análise de dados relevantes. (YIN, 2001, p. 41)

Dessa forma, o delineamento da pesquisa compreendida nesse artigo é o estudo de caso da empresa $A$ e o instrumento de aplicação do estudo de caso foi uma entrevista estruturada e formulada através de um protocolo denominado: modelo de checagem de utilização da Gestão de Design em MPEs do vestuário de moda; gerado pela pesquisadora Lucimar de Fátima Bilmaia Emídio em sua dissertação de mestrado no ano de 2006.

A entrevista que contempla esse modelo de checagem foi realizada pela autora deste artigo e os sujeitos participantes foram os proprietários, uma vez que estes conhecem as particularidades do processo, dos materiais, do produto e também de assuntos relacionados a finanças, recursos humanos e vendas, sendo agentes centralizadores na tomada de decisões e também das informações; conforme constatado e descrito por Emídio (2006) como sendo esta uma característica comum entre os proprietários de pequenas empresas do ramo da moda.

O modelo de checagem de utilização da gestão de design em MPEs do vestuário (EMIDIO, 2006), quadro 1 abaixo, foi desenvolvido com base em um referencial teórico baseado em pesquisas 
da autora sobre o que os autores recomendam para a prática de GD nas empresas. Dessa forma, ele serviu como roteiro para a realização da entrevista para com os proprietários da empresa $A$ e como direcionamento na obtenção do diagnóstico e das análises dos resultados.

Quadro 1: Modelo de checagem de utilização da Gestão do design em MPEs do vestuário de moda.

\begin{tabular}{|c|c|c|c|}
\hline $\begin{array}{l}\text { UNIDADES DE } \\
\text { ANÁLISE DA } \\
\text { PESQUISA }\end{array}$ & $\begin{array}{l}\text { VARIÁVEIS DA UNIDADE DE } \\
\text { ANÁLISE }\end{array}$ & ORIGEM & $\begin{array}{c}\text { PERGUNTA } \\
\text { NO } \\
\text { ROTEIRO }\end{array}$ \\
\hline $\begin{array}{l}\text { Dados da } \\
\text { empresa }\end{array}$ & $\begin{array}{l}>\text { segmento; } \\
>\text { número de funcionários; } \\
>\text { tempo de atuação/ dados históricos; } \\
>\text { produção mensal; } \\
\text { mercado de atuação e forma de } \\
\text { comercialização. }\end{array}$ & Yin (2001). & $\begin{array}{l}\text { Registros } \\
\text { iniciais. }\end{array}$ \\
\hline $\begin{array}{l}\text { Estrutura } \\
\text { organizacional } \\
\text { e os níveis de } \\
\text { tomada de } \\
\text { decisão }\end{array}$ & $\begin{array}{l}>\text { poder de decisão na empresa; } \\
\text { critérios utilizados para divisão do } \\
\text { trabalho e os mecanismos } \\
\text { incorporados para coordená-los; } \\
>\text { principal executivo da empresa/ } \\
\text { funções desempenhadas e sua } \\
\text { formação; } \\
>\text { cultura organizacional. }\end{array}$ & $\begin{array}{l}\text { Wood Junior (2002); } \\
\text { Motta e Vasconcelos (2004); } \\
\text { Montana e Charnow (2003); } \\
\text { Design Atlas (2006); } \\
\text { D'ajuz (2003 apud Martins 2004); } \\
\text { Araújo (2004); } \\
\text { Johann (2004); } \\
\text { Dias (2003); } \\
\text { Morgan (2002); } \\
\text { Chowdhury (2003). }\end{array}$ & $1,2,3,4,5,6$ \\
\hline $\begin{array}{l}\text { Ações de } \\
\text { design } \\
\text { relacionadas } \\
\text { ao processo } \\
\text { de } \\
\text { desenvolvimen } \\
\text { to de produto }\end{array}$ & $\begin{array}{l}\text { A - Quanto ao processo de } \\
\text { desenvolvimento e organização das } \\
\text { atividades: } \\
>\text { existência de um departamento de } \\
\text { desenvolvimento de produtos; } \\
>\text { responsável pelo processo de } \\
\text { desenvolvimento de produto; } \\
>\text { formação do profissional ou } \\
\text { (profissionais) que desenvolve(m) } \\
\text { esta atividade na empresa; } \\
>\text { nível de interação do profissional } \\
\text { designer ou da equipe de design } \\
\text { com outras áreas da empresa; } \\
>\text { metodologia/procedimentos } \\
\text { utilizada(os) pela empresa no } \\
\text { processo de desenvolvimento de } \\
\text { produto; } \\
\text { fontes de pesquisas utilizadas para } \\
\text { o desenvolvimento de produtos; } \\
\text { estágios do desenvolvimento de } \\
\text { produto que o designer participa. } \\
\text { B- Quanto à estratégia de produto: } \\
>\text { o que diferencia o produto dos } \\
\text { concorrentes; } \\
>\text { decisão sobre novos produtos na } \\
\text { empresa; } \\
\text { como são trabalhados os } \\
\text { elementos: absolessência } \\
\text { programada da moda e o novo como } \\
\text { imperativo categórico; } \\
>\text { os projetos de produtos são } \\
\text { desenvolvidos: por meio de } \\
\text { aperfeiçoamento de produtos } \\
\text { existentes; utilizando-se de idéias } \\
\text { ainda não experimentadas; mesma } \\
\text { utilização em categorias diferentes } \\
\text { ou outros; } \\
\text { como dar competitividade ao } \\
\text { produto; }\end{array}$ & $\begin{array}{l}\text { Burdek (2006); } \\
\text { Schulmann (1994); } \\
\text { Fornasier (2005); } \\
\text { Roda (2004); } \\
\text { Santos (2000); } \\
\text { Bersen (1987 } \\
\text { apud Santos, 2000); } \\
\text { Escorel (2000); } \\
\text { Bahiana (1998); } \\
\text { CPD (1997); } \\
\text { De Carli (2002); } \\
\text { Lipovetsky (1989); } \\
\text { Design Atlas (2006); } \\
\text { Sarquis (2003); } \\
\text { Ulrich \& Eppinger (1995 apud Sabino } \\
\text { Neto, Merino, 2004); } \\
\text { Montemezzo (2003); } \\
\text { Caldas (2004); } \\
\text { Kerzner (2002). }\end{array}$ & $\begin{array}{l}13,14,15,16,1 \\
7,18,19,20,21 \\
, 22 \\
23,24,25\end{array}$ \\
\hline
\end{tabular}


BUSO, Vanessa Zanardo; MARTINS, Rosane Fonseca de Freitas

\begin{tabular}{|c|c|c|c|}
\hline & $\begin{array}{l}\text { importância da pesquisa de } \\
\text { tendências. }\end{array}$ & & \\
\hline $\begin{array}{l}\text { Estratégias } \\
\text { Competitivas }\end{array}$ & $\begin{array}{l}>\text { avaliação do grau de satisfação de } \\
\text { seus clientes; } \\
>\text { como são monitoradas as forças } \\
\text { externas do macroambiente; } \\
>\text { principal fator de competitividade } \\
\text { da empresa; } \\
\text { principal dificuldade de crescimento } \\
\text { da empresa; } \\
>\text { como são trabalhadas as questões } \\
\text { das mudanças no ambiente } \\
\text { industrial; } \\
>\text { postura da empresa em relação a } \\
\text { concorrência. }\end{array}$ & $\begin{array}{l}\text { Costa e Silva (2002); } \\
\text { Jones (2005); } \\
\text { Nobrega (2004); } \\
\text { Chiavenato (2000); } \\
\text { Tachizawa \& Faria (2004); } \\
\text { Bulgacov (1999); } \\
\text { ttzberg (2003); } \\
\text { Ritto e Silva (2001); } \\
\text { Mintzberg \& Quinn (2001); }\end{array}$ & $\begin{array}{l}7,8,9,10,11 \\
12 .\end{array}$ \\
\hline $\begin{array}{l}\text { Papel da } \\
\text { atividade de } \\
\text { design no } \\
\text { desempenho } \\
\text { da qualidade } \\
\text { pelas MPEs }\end{array}$ & $\begin{array}{l}>\text { qualidade da matéria-prima antes da } \\
\text { fabricação; } \\
>\text { qualidade durante o processo de } \\
\text { fabricação; } \\
>\text { testes de controle de qualidade; } \\
>\text { inspeção antes da distribuição dos } \\
\text { produtos; } \\
>\text { qualidade do projeto. }\end{array}$ & $\begin{array}{l}\text { Manzini e Vezzoli (2005); } \\
\text { Roozemburg \& Eeckels(1995 apud } \\
\text { Van Der Lin, 2004). }\end{array}$ & 38. \\
\hline $\begin{array}{l}\text { Importância do } \\
\text { design para } \\
\text { empresa }\end{array}$ & $\begin{array}{l}>\text { na concepção do projeto; } \\
\text { na modelagem; } \\
\text { na produção; } \\
\text { na distribuição; } \\
>\text { na comercialização; } \\
>\text { na imagem. }\end{array}$ & $\begin{array}{l}\text { Treptow (2003); } \\
\text { Montemezzo (2002); } \\
\text { Demarchi (2000); } \\
\text { Santos (2000); } \\
\text { DMI (2005); }\end{array}$ & $\begin{array}{l}33,34 \\
35,36,37\end{array}$ \\
\hline $\begin{array}{l}\text { Nível de } \\
\text { informação de } \\
\text { design }\end{array}$ & $\begin{aligned} & \text { possibilidades de atuação do } \\
& \text { profissional designer de moda na } \\
& \text { empresa; } \\
&>\text { existência de um profissional } \\
& \text { designer de moda na empresa; } \\
&>\text { atividades desempenhadas pelo } \\
& \text { designer na empresa; } \\
&>\text { entendimento da relação dos } \\
& \text { elementos da gestão com o design, } \\
& \text { por parte da empresa; } \\
&>\text { o design é inserido na estratégia e } \\
& \text { no modelo de gestão da empresa; } \\
&>\text { benefícios gerados pela adoção da } \\
& \text { gestão do design como uma } \\
& \text { estratégia competitiva; } \\
&>\text { impacto de design no negócio da } \\
& \text { empresa; } \\
&>\text { relação das questões de } \\
& \text { investimento e retorno do design } \\
& \text { para a empresa. }\end{aligned}$ & $\begin{array}{l}\text { Mozota (2002); } \\
\text { Magalhães (1997); } \\
\text { Wolf (1998); } \\
\text { Design Atlas (2006); } \\
\text { Martins (2004); } \\
\text { Sarquis (2003); } \\
\text { Demarchi (2000); } \\
\text { Araujo (1996). }\end{array}$ & $\begin{array}{l}26,27,28,29, \\
30,31, \\
32 .\end{array}$ \\
\hline
\end{tabular}

Fonte: adaptado de EMIDIO, 2006, p. 81 a 84

Paralelamente e influenciando a análise dessa coleta de dados, foi realizada uma abordagem etnográfica comparativa realizada a partir de observações da presente autora que exerceu a função de designer da empresa A em um período de três meses no ano de 2011.

\section{Descrição dos resultados obtidos pela entrevista com os proprietários}

\section{1-Dados empresariais}

De acordo com os proprietários, a empresa iniciou suas atividades há quatro anos, atuando no segmento de complementos decorativos destinados às indústrias de confeç̧ão do Paraná. A proprietária fora representante comercial de uma marca de produtos termocolantes de Fortaleza e após entrar em contato com os meios produtivos de tal segmento, visando atingir o mercado 
consumidor do Paraná resolvera então montar seu negócio próprio. Inicialmente, toda a produção era feita manualmente com instrumentos de produção bem arcaicos. Atualmente, a produção é feita com a ajuda de maquinário específico.

Após várias mudanças, atualmente, a empresa A possui 10 funcionários fixos, sendo 1 secretária geral que contribui com serviços de RH, 2 funcionárias que cuidam da produção, 1 motorista que também presta serviços gerais, 1 funcionária que colabora com a parte administrativa e financeira, 1 funcionária que trabalha com a parte de produção que envolve o maquinário, 1 gerente de produção, 1 representante comercial e 2 designers de moda.

A produção mensal não fora revelada pelos proprietários afirmando ser esta bastante variável. A proprietária compra materiais de fornecedores de São Paulo, Londrina e também faz importação da China de pedrarias variadas. Todas as três máquinas de corte a laser também foram importadas da China.

A comercialização com os clientes resume-se da seguinte maneira: a representante comercial da empresa faz visitas às empresas de confecção da região norte do Paraná, tanto aos clientes fiéis quanto aos clientes eventuais. Nessas visitas são apresentadas as cartelas de materiais trabalhados pela empresa $\mathrm{A}$ e a partir disso a representante comercial juntamente aos proprietários e aos designers ou estilistas das empresas resumem aquilo que pode ser trabalhado. Dessa forma, a representante comercial repassa o que foi definido ao departamento de Criação da empresa A, para que sejam desenvolvidas as coleções exclusivas e individuais para cada marca. Trabalha-se uma média de quatro a cinco coleções por semana.

\section{2-Estrutura organizacional e níveis de tomada de decisão}

A direção geral da empresa A é composta pela atuação de um casal de proprietários. A proprietária, não tem curso de graduação e atua como supervisora geral de todos os processos e departamentos da empresa A e pela administração da comercialização dos produtos. O proprietário, por sua vez, atua mais na área de controle de finanças da empresa, sendo que ele é graduado em Educação física, mas atua há anos, paralelamente a empresa $A$, como representante de tecidos de uma empresa nacional; no território norte do Paraná.

Em termos de divisão e coordenação dos trabalhos e as tomadas de decisão, a empresa A se estrutura em departamentos, conforme Figura 1, e cada departamento se responsabiliza por realizar suas funções, sendo que todos os departamentos são controlados pela direção geral da empresa.

Figura 1 - Organograma fornecido pela empresa A

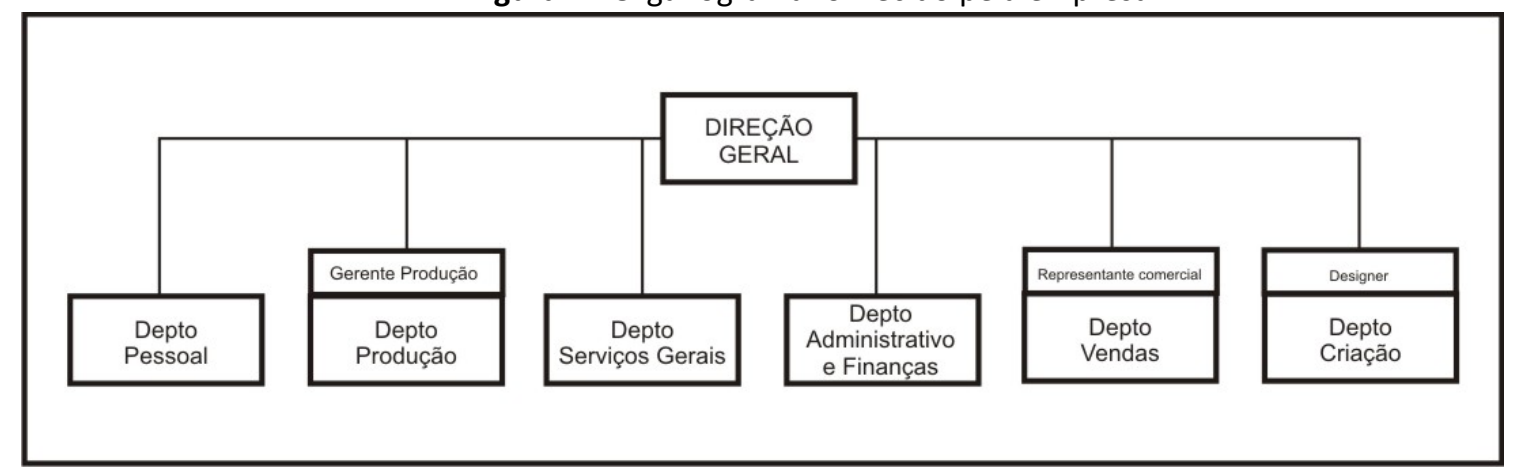

Em relação à cultura empresarial, os proprietários afirmam ser a empresa $A$ uma empresa familiar, pois desde o seu início a participação de membros familiares em diferentes departamentos fora o que contribuiu para a empresa se desenvolver e se transformar no que ela é hoje. Atualmente, a empresa se diversifica mais em busca de profissionais com especialização nas áreas que irão atuar; porém, ainda conta com a participação efetiva de familiares e amigos em alguns departamentos.

\section{3) Ações de design relacionadas ao processo de desenvolvimento de produto}

A) Quanto ao processo de desenvolvimento e organização das atividades: 
Os proprietários da empresa A afirmam existir um departamento focado para o desenvolvimento de produtos, cuja responsabilidade é do designer de moda contratado. Atualmente, no departamento de desenvolvimento de produtos, existe uma designer de moda, graduada nesta função e uma estagiária com graduação em design de moda prevista para o fim do ano de 2011.

De acordo com os proprietários, atualmente o departamento de design tende a atuar juntamente com as outras áreas da empresa para estabelecer melhorias constantes para o desenvolvimento e a produção dos produtos.

Por outro lado, os proprietários informaram que quanto aos procedimentos e metodologias utilizadas para o desenvolvimento, a empresa considera relevante realizar pesquisas de tendências, e dessa forma, eles investem na aquisição de materiais para pesquisa, conforme a necessidade do designer.

Embasado em pesquisas de tendências, o departamento de desenvolvimento de produtos delimita as coleções individuais direcionadas a cada cliente, a partir dos direcionamentos feitos pelas visitas da representante comercial aos clientes. $O$ próximo passo é feito com a produção dos protótipos aonde se testa o corte dos materiais e o resultado final destes. Quando aprovados, os protótipos dão seqüência à montagem das coleções totais, que são enviadas aos clientes para aprovação dos modelos indicados para posterior produção em volume.

B) Quanto à estratégia do produto:

Quando indagados sobre a concorrência, os proprietários pontuam que a qualidade dos materiais e o desenvolvimento de coleções exclusivas para cada cliente são os aspectos principais que os diferenciam dos demais concorrentes. Mescla-se ao departamento de desenvolvimento de produtos e à proprietária a decisão sobre novos produtos na empresa $\mathrm{A}$. Dessa forma, estes são desenvolvidos por meio de aperfeiçoamento de produtos já existentes; utilizando-se idéias novas e inéditas ou utilizando uma mesma idéia com aplicação diferente em termos de materiais para uma série de clientes.

Ainda sobre as estratégias relacionadas aos produtos, os empresários não se vêem a vontade com os termos "obsolescência programada da moda" e o novo como imperativo categórico; dessa forma, esses elementos ficam apenas para uma colocação posterior da própria autora.

\section{4-Estratégias competitivas}

No referente às questões de estratégias competitivas, a empresa $A$, enfrenta uma dificuldade com os concorrentes no fator preço. Os clientes afirmam existir opções mais baratas de produtos similares no mercado.

Em contrapartida a essa situação, mais uma vez fora mencionada pelos proprietários que o desenvolvimento de coleções individuais para cada cliente, com destaque para a exclusividade faz-se como uma ferramenta competitiva de grande valor e, seguidamente, a preocupação com a utilização de matéria-prima de qualidade superior e atualizada periodicamente também contribui positivamente com essa situação; fatores que agregam valor e explicam o preço mais alto praticado pela empresa $A$.

Por outro lado, a proprietária afirma que o contato diário que ela tem com os proprietários das empresas clientes fortalece a confiança destes com os produtos da empresa A; assim, o grau de satisfação dos clientes é dado por feedback direto dos clientes com a proprietária.

\section{5-Papel da atividade de design no desempenho da qualidade pela empresa}

A qualidade é um atributo que os proprietários fazem questão de citar como característica essencial para o desenvolvimento dos produtos e para o produto em si quando finalizado. Desde a preocupação com a excelência da matéria-prima até o controle dos produtos que são expedidos para os clientes.

Dessa maneira, referente ao controle de qualidade é feita uma vistoria da matéria-prima por parte da proprietária e dos funcionários do departamento de produção, juntamente à gerente de produção. Em seguida, todo o processo de produção é monitorado e, para finalizar, antes do processo de expedição todos os produtos são conferidos e assinados com vistoria por um responsável previamente definido pela gerente de produção. 
O projeto de design por sua vez, fica sob a responsabilidade do departamento de criação e da equipe de designers. Porém, a proprietária afirma ser muito importante a sua participação na finalização de todos os produtos, justamente por ela conhecer o perfil de seus clientes.

\section{6-Importância do design para a empresa}

Para a empresa $A$, a contribuição principal do design está no processo de desenvolvimento de produtos, com a utilização de um processo criativo sistematizado e com o domínio por parte do designer dos programas gráficos, como o corel drawn. A criatividade e a capacidade de lidar rapidamente com situações inusitadas ou que necessitam de procedimentos criativos rápidos também são características do design mencionadas pelos entrevistados.

Por outro lado, a proprietária afirma que o design faz-se importante por ser uma atividade que agrega os outros departamentos, no sentido em que se preocupa com os meios produtivos, com a otimização de matéria-prima e principalmente por agregar com relevância os insights que os demais departamentos acrescentam para o desenvolvimento de produtos.

\section{7-Nível de informação de design}

De acordo com os entrevistados, há aproximadamente dois anos a empresa conta com a participação no seu departamento de desenvolvimento de produtos de pelo menos um designer de moda. Desde então, o designer de moda tem a responsabilidade de desenvolver coleções de complementos decorativos termocolantes para os clientes da empresa $A$, respeitando os moldes de desenvolvimento já trabalhados pela proprietária desde o início da empresa.

Com a aquisição de maquinário específico para o corte a laser, necessário para a otimização dos processos de produção, surgiu a necessidade de domínio de outra estratégia de desenvolvimento e criação das coleções, provenientes do domínio de programas gráficos. Dessa forma, esse foi o principal motivo para o investimento da empresa A no profissional do design.

Por outro lado, a proprietária complementa com o quanto foi benéfico ao retorno financeiro e organizacional da empresa A, a contratação da primeira designer de moda. A partir disso, o investimento em um profissional da área de design é reconhecida pela proprietária como algo fundamental para o crescimento empresarial.

\section{Descrição dos resultados obtidos pela observação etnográfica comparativa}

A presente autora contribuiu como designer de moda na empresa A durante um período de três meses no ano de 2011. Dessa forma, torna-se relevante antecipar alguns pontos comparativos entre as respostas obtidas com a entrevista, realizada junto aos proprietários e a observação feita pela autora, durante seu tempo de atuação como designer na empresa.

O primeiro ponto a ser destacado é sobre o processo de comercialização dos produtos da empresa A. Definiu-se pelos proprietários, que a comercialização dos produtos é decorrente do desenvolvimento de coleções exclusivas aos clientes e que estas são desenvolvidas em um número de quatro a cinco por semana. Porém, a proprietária da empresa raramente respeita esse processo de desenvolvimento, acrescentando vários outros desenvolvimentos paralelos, definidos por ela com outros clientes, sem a comunicação prévia ao departamento de criação. Dessa forma, os processos se atrasam e a comercialização dos produtos fica defasada.

Seguidamente, ao descreverem sobre procedimentos e metodologias utilizadas para o desenvolvimento, os entrevistados revelaram considerar muito importante a realização de pesquisas de tendências para se desenvolver as coleções, e que dessa forma investem na aquisição de materiais específicos para tal finalidade. Discordando parcialmente, a autora afirma que apesar da consideração que a proprietária demonstra para a pesquisa de tendências, o mais importante é o volume de peças que são desenvolvidas por dia, o que condiciona muito pouco tempo para pesquisas e, além disso, todo o material de pesquisa adquirido para a empresa $\mathrm{A}$ foi escolhido apenas pela proprietária, sem a devida participação do designer nesta escolha.

Ainda sobre o processo de desenvolvimento de produtos, os empresários discorrem que o 
departamento de desenvolvimento de produtos delimita as coleções direcionadas a cada cliente a partir dos direcionamentos feitos pelas visitas da representante comercial aos clientes. Isso de fato ocorre e implica três observações:

Primeira, o designer da empresa A não obtém contato direto com os clientes, distanciando e tornando o processo de desenvolvimento mera concordância com um universo de delimitações vagas. Outro ponto é que, a empresa A por critério estabelecido pela proprietária não exige dos clientes um briefing de coleção, o que dificulta a correlação de cores, formas e demais atributos das peças dos clientes para a qual são definidos os produtos da empresa $A$.

Por fim, esse sistema de desenvolvimento de múltiplas coleções é interessante, pois demonstra às empresas o quanto exclusivos são os produtos definidos para elas; porém, muitas vezes a visita da representante comercial torna-se mais interessante quando já se possui uma coleção universal de produtos termocolantes que demonstrem as tendências antecipadas pela empresa $A$, que podem ser já utilizadas, apenas adaptando ou alterando algum aspecto desses produtos.

Por outro lado, o desenvolvimento de novos produtos, que compõem as diversas coleções exclusivas, muitas vezes não é respeitado; de forma que a proprietária exige a repetição de modelos para mais de um cliente. Ela alega que utilizar-se de uma mesma forma ou desenho alterando-se às vezes o material ou as cores das pedras é uma ferramenta que evita o desperdício de produtos que não foram aprovados por um cliente e podem ser aprovados por outros clientes.

A obsolescência programada da moda é engrenagem para a empresa $A$ uma vez que, para acompanhar as tendências das indústrias de confecção, os produtos termocolantes propostos pela empresa A devem estar em constante reciclagem e alteração. Contudo, a pesquisa por materiais e a reciclagem destes é muito desorganizada e sem critérios de pesquisa e os materiais são definidos apenas por escolha da proprietária.

No que tange a vistoria da matéria-prima, tanto das pedrarias quanto dos tecidos e das etiquetas, bem como a sua aplicação como termocolante, ressalta-se que muitas vezes não é testada o suficiente e acaba causando problemas quando a coleção já está definida. Isso requer uma atenção especial por parte da equipe de designers e da gerencia de produção. 0 processo produtivo por sua vez, é bastante específico, principalmente quando são diferentes pedrarias em uma mesma arte. Resumidamente esse processo é feito em etapas de encaixe de placas, cada uma com um tamanho ou uma cor de pedras, e dessa forma, estas placas devem ser conferidas no início do processo de encaixe para que não haja problemas depois de produzidas uma série delas. Dessa forma, é necessária a conscientização por parte da proprietária de que fazer testes de materiais e processos produtivos despendem um tempo relativamente menor do que o tempo e o material que é perdido quando há algum problema por falta de vistoria.

Sob outro aspecto a proprietária relata que a sua participação na finalização dos produtos é definitiva, pois ela conhece o perfil dos clientes. Essa afirmativa tem dois lados que merecem uma análise por parte de quem já atuou como designer da empresa A. O primeiro é o fato de que muitos insights positivos podem ser colocados pela proprietária no projeto de produtos, acrescentando idéias positivas. Por outro lado, a proprietária, muitas vezes acaba por 'barrar' idéias que o designer projetou e que seriam relevantes do ponto de vista do profissional para aquela coleção.

Finalmente, as questões que os proprietários relataram sobre a importância do design para a empresa e o nível de informação de design que a empresa mantém, confirma as observações feitas pela autora. A proprietária correlaciona o design como uma função operacional de criação e domínio de programas gráficos; porém, ela faz-se muito receptiva a aceitar e a entender cada vez mais a importância do design como uma estratégia que trabalha a interdisciplinaridade em favor do crescimento organizacional.

\section{Ações de gestão do design}

De acordo com os dados levantados pela entrevista feita com os proprietários e a partir dos dados acrescentados pela observação etnográfica da presente autora, serão enumeradas algumas ações de design que se estenderão como uma estratégia de gestão do design a fim de solucionar 
A Gestão de Design como estratégia organizacional em uma empresa ... termocolantes de Londrina-PR

problemas organizacionais. Essas ações demonstram, além de outras questões, a carência estratégica para a efetiva consistência organizacional da empresa A.

Cabe ressaltar que todas as ações propostas a seguir têm fundamentação teórica e bibliográfica defendida também neste artigo. São elas:

Quanto ao processo de desenvolvimento de coleções:

1) Pré-definição das coleções semanais a serem desenvolvidas: essa pré-definição deve ser realizada uma vez por semana em reunião com o designer, a representante comercial e a proprietária; para que fiquem claros a todos os objetivos e atividades semanais do departamento de criação;

2) Sistematização entre os designers e a proprietária de um horário fixo diário para a realização dos desenvolvimentos esporádicos desprendidos das coleções;

3) Contratação de profissionais freelances para contribuir com o desenvolvimento de coleções. A equipe de design fica então responsável por monitorar e definir quais as coleções destinadas a esses profissionais, a fim de que este não seja um processo desorganizado e que pelo contrário, seja de fato uma ferramenta para agregar contribuições criativas e otimizar tempo de desenvolvimento;

Sobre procedimentos e metodologias utilizadas para o desenvolvimento de coleções:

4) Programar um horário quinzenal em que o designer tenha oportunidade de reciclar sua pesquisa de tendências e em seguida;

5) Delimitar uma reunião também quinzenal entre os designers, os proprietários e a representante comercial para que as pesquisas de tendências sejam discutidas e divulgadas entre eles;

6)Definir uma rotina para a renovação dos materiais para as coleções. Nesse caso, é de extrema importância que o designer participe da definição da matéria-prima, uma vez que esta é um dos principais subsídios para o desenvolvimento de coleções;

7)Ao inserir novos materiais para as coleções, esses necessitam ser catalogados e estar sempre em vista dos clientes. A empresa $A$ tem um catálogo de pedrarias, o qual coloca à disposição para cada cliente. Porém, os tecidos por estarem em constante mudança tornam inviável a produção de mostruário para todos os clientes. Dessa forma, deve-se montar um mostruário virtual com a foto dos tecidos e as descrições dos mesmos. Durante a visita da representante comercial aos clientes, este fica então em contato direto com os materiais, mas, sempre que precisam, os clientes dispõem de uma visualização virtual permanente;

6)Estreitar a relação do departamento de design com os clientes. O contato do cliente com o designer é muito importante e dessa forma, a proprietária deve incentivar visitas dos clientes à empresa ou proporcionar o atendimento in loco a clientes de maior importância, uma vez que a observação e o entendimento da coleção produzida pelos clientes geram grandes possibilidades para o desenvolvimento dos complementos decorativos termocolantes destinados às peças;

7)É fundamental para o bom trabalho de uma equipe de designers que o desenvolvimento de coleções respeitem um briefing de coleção. Dessa forma, a empresa A deve adquirir a cultura de exigir dos clientes o briefing de coleção-para que sejam executados produtos pautados na idéia total do projeto de produto dos clientes. Esse fator estreita a possibilidade de unidade visual da coleção de complementos decorativos termocolantes com a proposta dos clientes, e evita que sejam projetados modelos que não contém linguagem visual relacionada às peças dos clientes;

8)Realização de mini-coleções quinzenais que traduzam as tendências pesquisadas pela empresa A em termos de combinação de cores, combinação e sobreposição de materiais, novidades em formas; ou seja, produtos sem marca definida que carregam idéias aos clientes como uma forma de "pronta-entrega";

Referente ao controle de qualidade:

10) Fazer testes com todos os materiais adquiridos e uma vez aprovados catalogá-los sistematicamente. Materiais não aprovados devem ser descartados e retirados da área em que ficam os aprovados para evitar confusão;

11) O gerente de produção deve monitorar o processo produtivo, garantindo o bom 


\section{Considerações finais}

As ações de design definidas compõem uma proposta inicial para fazer com que a empresa A caracterize-se como uma organização em que o design contribui para o crescimento e a evolução permanente desta.

A "estratégia de design define como a organização pretende utilizar o design, e como o processo de design pode melhor servir às suas necessidades operacionais" (BEST, 2003, p.49). Nesse sentido, uma estratégia de gestão de design só é alcançada quando operações de design no departamento de desenvolvimento e criação são trabalhadas sistematicamente e em conjunto com os demais departamentos, mobilizados como pensadores de design.

Dessa forma, o designer de moda na empresa A, é responsável por gerir os aspectos funcionais, visuais e ergonômicos dos produtos em uma constante em que se relacionam a melhoria da qualidade dos produtos, a busca por alternativas de materiais viáveis, o aperfeiçoamento dos processos de teste e de produção, o compromisso ambiental e as relações estéticas e de segurança que aproximam o produto do seu público consumidor. Nesse aspecto, o design tem um compromisso de valor em nível estratégico que adéqua as expectativas do mercado consumidor à capacidade produtiva empresarial como um todo.

O objetivo geral de propor contribuições da gestão do design ao bom funcionamento do departamento criativo da empresa A demonstra a importância do pensamento do design como uma ferramenta de criação de valor em uma organização em sua totalidade, o que fora atingido com a delimitação de ações de design interdisciplinares propostas ao departamento em questão.

Quanto aos objetivos específicos realizou-se uma pesquisa capaz de relacionar conceitos da gestão de design com a prática do design thinking que fundamenta o quanto é possível e necessário que os departamentos de uma empresa desvinculados da atuação direta de designers pratiquem ações de design integradoras.

Vale ressaltar que após a adoção e efetivação das ações de design propostas neste trabalho, convém que procedimentos de análise e monitoramento de resultados sejam realizados constantemente, visando constatar a eficiência de cada ação e os benefícios indiretos agregados paralelamente a estas.

Finalizando, destaca-se que para a conclusão deste trabalho fora fundamental o apoio e a contribuição da direção geral da empresa $\mathrm{A}$, ao proporcionar a coleta de dados através da entrevista e ao manter-se participativa e interessada pelos resultados e propostas de tal estudo.

\section{Referências}

APL VESTUÁRIO. Plano de desenvolvimento no arranjo produtivo local de vestuário de Cianorte/ Maringá - Paraná. Cianorte/Maringá, 2006. Disponível em < http://www.mdic.gov.br/arquivos/ dwnl_1248271195.pdf >. Acesso em 14 jun 2011.

BARONE, Vanessa. Crise barateia etiqueta e abre novos mercados, 2009. Disponível em < http:// www.global21.com.br/informessetoriais/setor.asp?cod=11 >. Acesso em 15 jun 2011.

BEST, Kathryn. Design Management: Managing Design Strategy, Process and Implementation.

Switzerland: AVA, 2006.

BROWN, Tim. Design thinking: uma metodologia poderosa para decretar o fim das velhas idéias: Elsevier, 2010. Traduzido de Change by design: how design thinking transforms organizations and inspires innovation. New York: HarperCollins, 2009.

CENTRO PORTUGUÊS DE DESIGN. Manual de gestão do design. Porto, 1997. 
A Gestão de Design como estratégia organizacional em uma empresa ... termocolantes de Londrina-PR

DEMARCHI, Ana Paula Perfetto; FORNASIER, Cleuza Bittencourt Ribas; MARTINS, Rosane Fonseca de Freitas. Processo de design com abordagem de design thinking. In: MARTINS, Rosane F. F; VAN der LINDEN, Júlio (org). Pelos Caminhos do Design: Metodologia do Projeto. Londrina: Eduel, 2012.

Design thinking no processo de Gestão de design: um estudo de caso na agricultura familiar. In 9o Congresso Brasileiro de Pesquisa e Desenvolvimento em Design, 2010. São Paulo. Anais... São Paulo: AEND-BR; Universidade Anhembi Morumbi, 2010.

EMIDIO, Lucimar de Fátima Bilmaia. A Gestão de design como ferramenta estratégica para MPE's do vestuário de moda: um estudo de caso na região de Londrina. 128f. Dissertação ((Mestrado em Desenho Industrial) - Universidade Estadual Paulista. Faculdade de Arquitetura, Artes e Comunicação, Bauru, 2006.

FIEP. Indústria Têxtil no Paraná. Curitiba, 2008. Disponível em < http://www.fiepr.org.br/fiepr/ analise/panorama/t\%C3\%AAxtil.pdf >. Acesso em 25 mai 2011.

GIL, Antonio Carlos. Como elaborar projetos de pesquisa. 4. ed. São Paulo: Atlas, 2002.

HSMMANAGMENT. O pensamento de design de David Kelley. 2009, p. 185

LOCKWOOD, Thomas. Design thinking: Integrating innovation, customer experience, and brand value. New York: Allworth Press, 2006.

MAUBORGNE, Renée; KIM, W. Chan. A estratégia do oceano azul: Como criar novos mercados e tornar a concorrência irrelevante. Elsevier, 2005.

MOZOTA, Brigitte Borja de. Design management. Paris: Éditions d’Organization, 2002.

YIN, Robert. K. Estudo de Caso: planejamento e métodos. 2.ed. Porto Alegre: Bookman, 2001. 